\title{
Seasonal Predictability and Change of Large-Scale Summer Precipitation Patterns over the Northeast United States
}

\author{
KUK-HYUN AHN \\ Department of Civil and Environmental Engineering, KongJu National University, Cheon-an, South Korea \\ SCOTT STEINSCHNEIDER \\ Department of Biological and Environmental Engineering, Cornell University, Ithaca, New York
}

(Manuscript received 3 December 2018, in final form 4 March 2019)

\begin{abstract}
This study examines space-time patterns of summer daily rainfall variability across the Northeast United States, with a focus on historical trends and the potential for long-lead predictability. A hidden Markov model based on daily data is used to define six weather states that represent distinct patterns of rainfall across the region, and composites are used to examine atmospheric circulation during each state. The states represent the occurrence of region-wide dry and wet conditions associated with a large-scale ridge and trough over the Northeast, respectively, as well as inland and coastal storm tracks. There is a positive trend in the frequency of the weather state associated with heavy, regionwide rainfall, which is mirrored by a decreasing trend in the frequency of stationary ridges and regionwide dry conditions. The frequency of state occurrences is also examined for historical Northeast droughts. Two primary drought types emerge that are characterized by region-wide dry conditions linked to a persistent ridge and an eastward-shifted storm track associated with light precipitation along the coastline. Finally, composites of May sea surface temperature anomalies (SSTAs) prior to summers with high and low frequencies of each weather state are used to assess long-lead predictability. These composites are compared against similar composites based on regional anomalies in low streamflow conditions [June-August 7-day low flows (SDLFs)]. Results indicate that springtime SSTs, particularly those in the Caribbean Sea and tropical North Atlantic Ocean, provide some predictability for summers with above-average precipitation and SDLFs, but SSTs provide little information on the occurrence of drought conditions across the Northeast.
\end{abstract}

\section{Introduction}

Precipitation in the Northeast United States is generally less variable than other regions of the country (Groisman and Easterling 1994). Consequently, the impacts of precipitation variability and change on key economic sectors like agriculture have received less attention than in regions like California, the Midwest, and the Great Plains (Gowda et al. 2018). However, precipitation and streamflow in the Northeast have been increasing over the last several decades (Kunkel et al.

Supplemental information related to this paper is available at the Journals Online website: https://doi.org/10.1175/JHM-D-180252.s1.

Corresponding author: Kuk-Hyun Ahn, ahnkukhyun@ gmail.com
2013), particularly in the summer and in the frequency of extreme events (Frei et al. 2015; Huang et al. 2018; Huntington and Billmire 2014; Kunkel et al. 2013; Peterson et al. 2013). These trends can lead to increased flooding and exacerbate waterlogged conditions that are detrimental to agricultural production (Wolfe et al. 2018). In addition, despite an increasing trend in regional precipitation, drivers of summertime climate in the eastern United States are also becoming more variable ( $\mathrm{Li}$ et al. 2012), and short-term droughts can cause significant damage because stakeholders in the Northeast are ill prepared to manage their impacts. For example, the recent drought in 2016 caused crop failures near $30 \%$ across large areas of rain-fed farmland and significant monetary losses in the agricultural community (Sweet et al. 2017). Such droughts are projected to become more common with climate change (Melillo et al. 2014). As climate in the Northeast continues to 
change and become more variable, there is a need to better understand the pathways that link large-scale modes of atmospheric circulation to interannual variability in regional precipitation and hydrology. Such knowledge would be particularly helpful if tailored for the summer, to help develop long-lead ( $>1$ month) climate forecasts that could help promote adaptive management in the agricultural and water sectors under climate change (Hall et al. 2014; Steinschneider and Brown 2012a).

The dynamical processes affecting precipitation and streamflow in the Northeast vary by season. In the summer, rainfall is often caused by frontal systems associated with extratropical storms traversing northern New England and Canada, although there is a secondary near offshore track influencing the coastal region (Agel et al. 2015; Towey et al. 2018). These tracks are especially prominent during extreme rainfall events, which are most intense during summer. Warm season rainfall associated with elongated cold fronts, mesoscale convective systems, and highly localized convection are also common, and are often associated with warm, humid air masses from the Gulf of Mexico and tropical Atlantic Ocean (Frei et al. 2015; Kunkel et al. 2012). However, the most intense and widespread rainfall across the region is associated with infrequent tropical storms and hurricanes.

The large-scale patterns of atmospheric circulation that control variability in Northeast summertime precipitation vary across the associated rainfall mechanisms described above, and many have been previously identified through weather typing (Agel et al. 2018, 2019; Marquardt Collow et al. 2016). During widespread heavy rainfall events associated with extratropical storms, a west-east dipole of low and high surface pressure over the Plains and Great Lakes travels eastward and advects moisture into the Northeast from the Gulf of Mexico, while divergence aloft promotes convergence, vertical motion, and enhanced rainfall (Marquardt Collow et al. 2016). Agel et al. (2018) identified a similar synoptic-scale dipole event, but also identified separate, isolated troughs and ridges associated with nontropical regional extremes. During tropical storm events, a low pressure system originates farther south and often traverses north along the coastline (Marquardt Collow et al. 2016). Even in the absence of storm events, summertime rainfall can be enhanced or suppressed by larger-scale mechanisms affecting mean flow moisture advection over the region. For instance, Li et al. (2012) demonstrated that variations in the western ridge of the North Atlantic subtropical high (NASH) control regional low-level moisture transport over the eastern United States, such that a southwest (northwest) shift in the western ridge position leads to wet (dry) conditions over much of the region. Building from these results, Carter and Steinschneider (2018) recently showed that west-east variations in the position of the NASH are related to late spring and early summer rainfall anomalies over the northeastern United States and Canada that can contribute to flooding in the Great Lakes.

There is an ongoing debate regarding whether any of the circulation patterns above are forced by underlying sea surface temperature anomalies (SSTAs) or other boundary conditions that would enable effective seasonal forecasts of summer rainfall in the Northeast. Several empirical studies have suggested such forecasts are possible. For instance, Steinschneider and Brown (2011) found that summertime low flows in the Connecticut River basin were significantly related to the springtime North Atlantic Tripole (NAT), an SSTA pattern composed of three lobes with one centered off the eastern coast of the United States and the other two bounding the first with an extended reach from the coast of Florida to an area south of Greenland. Further work suggests that extended forecasts (1-3-month lead) of low flows based on the NAT are possible across the Northeast (Ahn et al. 2017; Steinschneider and Brown 2012b). The NAT has previously been shown to represent the SST response to a winter NAO (Marshall et al. 2001) and midtropospheric height anomalies off the eastern coast of Newfoundland in the spring (Seager et al. 2012). It has also has been linked with feedbacks on atmospheric circulation in the spring (Peng et al. 2002) and summer (Gastineau and Frankignoul 2015; Ossó et al. 2018). These feedbacks provide a physical basis for the NAT forecast signal in the Northeast, and a possible explanation for empirical studies that have also found significant relationships between the wintertime NAO and Northeast summertime streamflow indices (Armstrong et al. 2014; Berton et al. 2017; Coleman and Budikova 2013). In addition, variations in the spring NAT have been linked to variability in the position of the NASH western ridge (Doering and Steinschneider 2018). Modeling experiments have shown that warm waters in the tropical Atlantic lobe of the NAT (i.e., the Atlantic warm pool) can incite a Gill-type sea level pressure response (Gill 1980) over the Gulf of Mexico that weakens the NASH and displaces its core to the southwest (Kushnir et al. 2010; Schubert et al. 2009; Seager and Hoerling 2014; Wang et al. 2008, 2007, 2010; Weaver et al. 2009). This response could form part of the feedback between the spring NAT and summer atmospheric flow that underscores the observed seasonal forecast skill in the Northeast.

However, in contrast to the empirical studies above, model-based assessments of seasonal predictability across North America have been unable to identify any 
robust signals over the Northeast (Schubert et al. 2009; Wang et al. 2010; Wang and Schubert 2014). Seager et al. (2012) focused explicitly on the Catskill region in the Northeast, and was unable predict any precipitation anomalies during the last half century using a multimodel ensemble forced with historical SSTAs. They concluded that past droughts and pluvials in that region were therefore the result of internal atmospheric variability with little to no potential for seasonal predictability. One potential explanation for these conflicting results is that many of the empirical studies above were primarily based on streamflow records, rather than precipitation. There is therefore the potential that predictability was overstated due to the effects of hydrologic memory. That is, the springtime Atlantic signal linked to the winter NAO and spring NAT could have affected springtime precipitation, which then influenced streamflow in the following summer, rather than influencing summertime storm tracks and atmospheric moisture directly. Alternatively, the model-based results could differ from empirical studies because they are not sufficiently targeted toward Atlantic SSTA influences on the Northeast region in the summer. For instance, Seager et al. (2012) only assessed annual precipitation predictability in the Catskills region. Many other model-based studies (Schubert et al. 2009, 2016; Wang et al. 2010; Wang and Schubert 2014) focus on annual precipitation responses to major modes of climate variability like the El Niño-Southern Oscillation (ENSO), Pacific decadal oscillation (PDO), and Atlantic multidecadal oscillation (AMO), or on seasonal responses in other regions of North America with more variable precipitation. In addition, some modeling results have shown spatial biases in coupled oceanic-atmospheric dynamics related to the NAT signal, which also might degrade modelbased forecasts based on the NAT (Hu and Huang 2007).

This paper contributes an empirical study of antecedent, large-scale climate conditions that precede summertime [June-August (JJA)] droughts and wet periods in the Northeast with a focus on long-lead predictability. The overarching goal of this work is to better determine the source and strength of the empirical forecasting signal of regional-scale summer precipitation patterns over the Northeast based on antecedent SSTAs, with an emphasis on the Atlantic basin. Building from the work in Agel et al. (2018) and Marquardt Collow et al. (2016), we employ a hidden Markov model (HMM) to identify weather types of summertime climate associated with space-time patterns of daily precipitation across the Northeast. Our approach advances past weather typing analyses in the Northeast in several ways: 1 ) we focus exclusively on the summer; 2) we assess weather patterns associated with all precipitation, not just extreme events, providing a more relevant analysis for both drought and pluvials; and 3) we use an HMM to identify weather patterns as latent states that are inferred from space-time patterns in the underlying precipitation data, rather than directly from larger-scale synoptic fields. After the states are identified, we establish their association with large-scale atmospheric circulation, evaluate the seasonality and long-term trends of state occurrences, and assess their frequencies during past droughts events. We then present a novel assessment of seasonal forecast potential targeted toward the weather states using composites of springtime SSTAs that precede each weather type. A similar analysis is conducted for JJA 7-day low flows in the Northeast, and these results are compared to determine whether precipitation-derived weather regimes and low flows share similar forecasting signals, and if so, which weather states are best associated with these signals.

\section{Data}

Daily precipitation data for 93 meteorological stations are used in the HMM analysis (Fig. 1). Precipitation observations for 60 years between 1958 and 2017 are obtained from the Global Historical Climatology Network (GHCN) daily dataset (https://www.ncdc.noaa.gov/ ghen-daily-description; Menne et al. 2012). Stations are selected based on the following two criteria: 1) they are located in the Northeast United States, defined here as including Pennsylvania, northern New Jersey, New York, Connecticut, Massachusetts, Rhode Island, Vermont, New Hampshire, and Maine, and 2) they have no more than 552 missing values (i.e., $10 \%$ of the entire period) in the daily summer record over 60 years. We also use the CPC Unified Gauge-Based Analysis of Daily Precipitation gridded dataset (Chen et al. 2008) for composite analyses and to define antecedent precipitation conditions for the study watersheds.

Daily streamflow data at 52 U.S. Geological Survey (USGS) streamflow gauges (Fig. 1) throughout the Northeast are acquired from the Geospatial Attributes of Gages for Evaluating Survey (GAGES II) database (Falcone et al. 2010). Two screening procedures are applied in gauge selection: 1) only "reference gauges" in GAGES II that are relatively unaltered by anthropogenic activity are selected, and 2) all gauges have no missing values over the summer period (JJA) from 1958 to 2017. Seasonal 7-day low flows (SDLFs), defined here by the lowest 7-day mean streamflow in each JJA season, are calculated for each gauge to quantify extreme low-flow conditions in each summer.

To explore large-scale atmospheric circulation during each weather state, we collect daily mean geopotential 


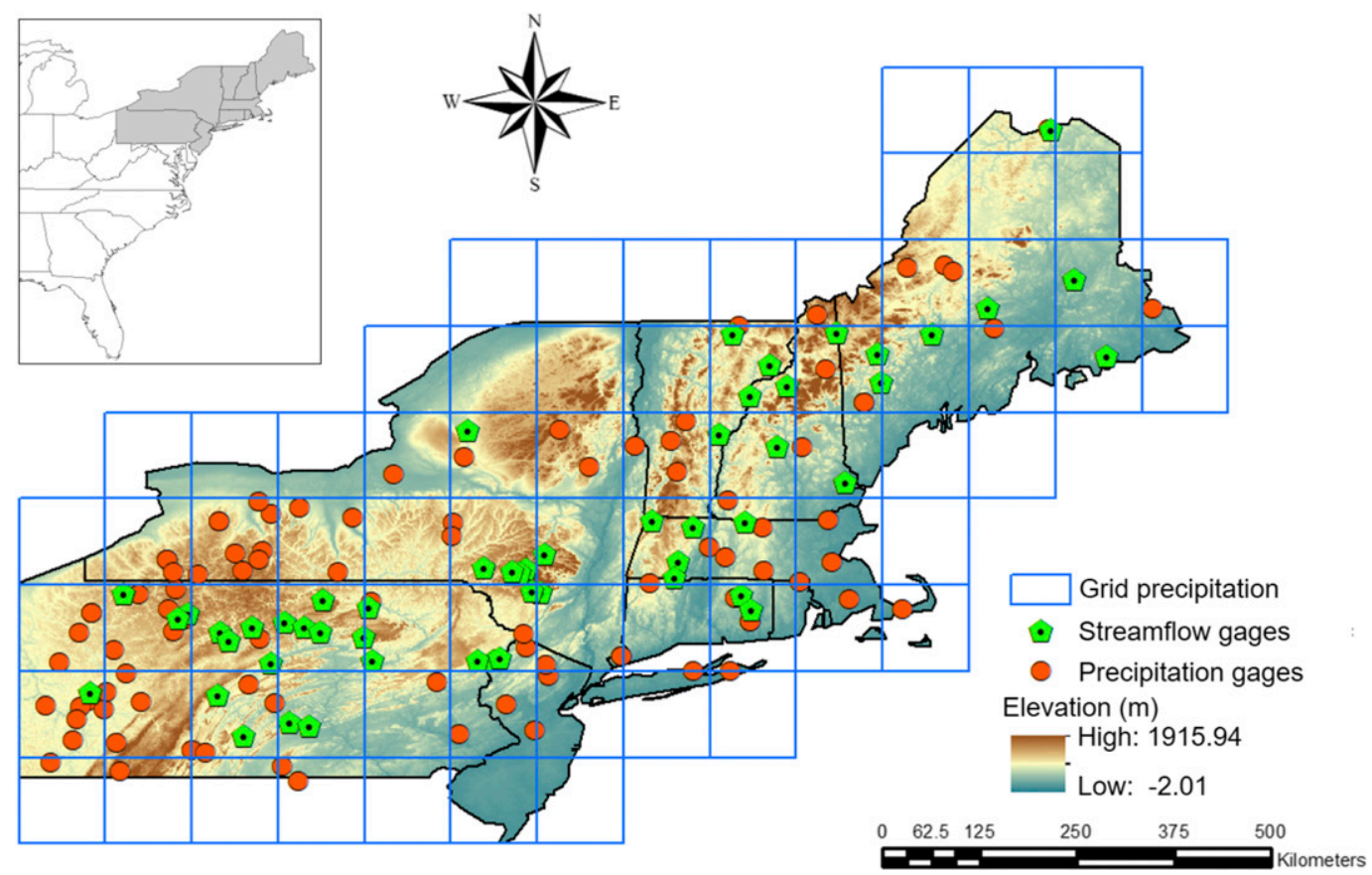

FIG. 1. Location of the selected 93 rainfall gauges, 52 streamflow gauges, and $1^{\circ} \times 1^{\circ}$ grid for CPC precipitation in the Northeast.

heights and vertical and meridional wind speed anomalies between 1958 and 2017 from the National Center for Atmospheric Prediction- National Centers for Environmental Prediction (NCAR-NCEP) Reanalysis 1 project (Kalnay et al. 1996). We extract 850- and 300-hPa height anomalies to characterize lower- and upper-level flow, and also calculate vertically integrated water vapor transport (IVT) to characterize moisture availability:

$$
\begin{aligned}
\mathrm{IVT} & =\sqrt{\mathrm{IVT}_{u}^{2}+\mathrm{IVT}_{v}^{2}}, \\
\mathrm{IVT}_{u} & =\int_{1000}^{300} \frac{u q}{g} d p, \text { and } \\
\mathrm{IVT}_{v} & =\int_{1000}^{300} \frac{v q}{g} d p .
\end{aligned}
$$

Here, $u$ and $v$ are daily mean zonal and meridional wind speeds, $q$ is daily mean specific humidity, $p$ is pressure level, and $g$ is the standard acceleration of gravity $\left(9.8 \mathrm{~m} \mathrm{~s}^{-2}\right)$. Daily SSTAs are collected from the Extended Reconstructed Sea Surface Temperature version 5 dataset (ERSSTv5; Huang et al. 2017). The reanalysis and SSTA data are selected to ensure our results are robust over a relatively long record. However, we also collect the atmospheric data mentioned above from ERA-Interim (Dee et al. 2011) over a shorter period (1979-2017) to verify the results of the analysis.

\section{Methodology}

\section{a. Hidden Markov model}

HMMs are a doubly stochastic model in which the daily probability of rainfall occurrences across a network of gauges is conditioned on a small number of latent (i.e., unobservable) states that are modeled as a Markovian process (Thyer and Kuczera 2000; Robertson et al. 2004, 2006). Let $\mathbf{R}_{t}=\left(R_{t}^{1}, R_{t}^{2}, \ldots, R_{t}^{I}\right)$ be a vector of precipitation occurrences on day $t(t=1, \ldots, T)$ for a network of $I$ precipitation stations $(T=5520$ and $I=93$ in this study). Let the observed value $R_{t}^{i}=1$ if rain occurs on day $t$ at station $i$ and $R_{t}^{i}=0$ otherwise. Here, rainfall occurrence is defined for any nonzero amount. The probability of rainfall occurrence at each precipitation gauge is assumed to vary across $H$ latent weather states, $S_{t} \in\{1,2, \ldots, H\}$, and the occurrences in time $t$ are only dependent on the current weather state $S_{t}$ :

$$
P\left(\mathbf{R}_{t} \mid S_{1: t}, \mathbf{R}_{1: t-1}\right)=P\left(\mathbf{R}_{t} \mid S_{t}\right) .
$$

In addition, the hidden state process $S_{1: T}$ is assumed to follow a first-order Markovian process:

$$
P\left(S_{t} \mid S_{1: t-1}\right)=P\left(S_{t} \mid S_{t-1}\right) .
$$

This process is modeled using a homogeneous $H \times H$ transition probability matrix. In addition, precipitation occurrences at each station at time $t$ are assumed to be 
independent of observations at other stations at time $t$, after conditioning on the hidden state:

$$
P\left(\mathbf{R}_{t}=d \mid S_{t}=h\right)=\prod_{i=1}^{I} P\left(R_{t}^{i}=d \mid S_{t}=h\right)=\prod_{i=1}^{I} P_{\mathrm{hid}},
$$

where $d \in\{0,1\}$, each $P_{\text {hid }} \in[0,1]$, and $P_{h i 0}+P_{h i 1}=1$. The probabilities of rainfall occurrence within each state, daily sequence of states, and the transition probabilities between states are inferred using the historical record of daily rainfall occurrences. The parameters of the model are estimated using the expectationmaximization algorithm (EM), an iterative maximum likelihood method (Celeux and Govaert 1992). The most probable sequence of states is estimated using the Viterbi algorithm (Rabiner 1989). These analyses are conducted using the depmixS4 package in the $\mathrm{R}$ programming language (Visser and Speekenbrink 2010). The inferred sequence $S_{1: T}$ is then analyzed to examine how spatial patterns of precipitation occurrence have varied over time, including their average progression during the summer season, trends across the entire 60-yr record, and observed frequencies during major droughts.

\section{b. Composite analysis for summer/spring teleconnections}

Composites are used to characterize the relationship between large-scale atmospheric-oceanic circulation patterns and the HMM states to identify underlying teleconnections. We first composite lower $(850 \mathrm{hPa})$ and upper $(300 \mathrm{hPa})$ level geopotential height, IVT, and precipitation anomalies for all days assigned to each weather state. Detrended May SSTAs are then composited over the 10 years with the highest and lowest frequencies of occurrence for each state. We use May SSTAs to focus our analysis on late spring conditions, although results are not significantly different when based on March-May (MAM) SSTAs. Statistical significance of the SSTA composites are tested using a twosided bootstrapping test with 1000 samples (Efron 1992).

We also explore whether SDLFs in the Northeast have similar spring forecasting signals to those for the precipitation states. To eliminate the effects of spring hydrologic memory on summer low flow, SDLFs at each gauge are first regressed against several proxies for antecedent conditions, including May streamflow, AprilMay CPC precipitation, and May CPC precipitation averaged within the watershed boundaries for each gauge provided by GAGES II. While soil moisture is arguably the best measure of antecedent moisture, it is not considered here due to limited data availability over the study domain and period of analysis. The proxy that best explains SDLFs across the region is selected, and

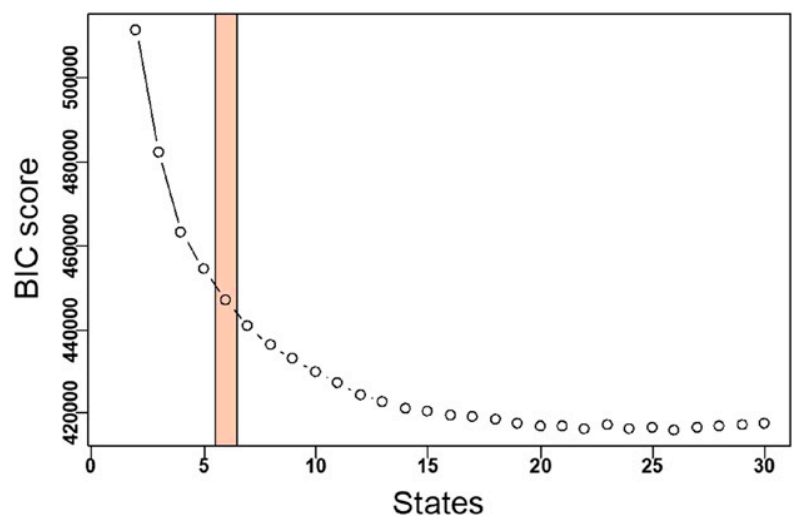

FIG. 2. The BIC for 2-30 hidden states in the HMM. The BIC at six states is highlighted.

the space-time variability of the regression residuals using that proxy are then summarized using empirical orthogonal function (EOF) analysis and a Varimax rotation (Horel 1981). The rotated EOFs (REOFs) provide a more localized representation of SDLF variability across the Northeast compared to the original EOFs. Similar to the analysis for the weather states, May SSTAs are composited over the 10 years with the highest and lowest values of the rotated principal components (RPCs). These composites are compared against those for the weather states to determine the level of agreement between the effects of springtime SSTAs on patterns of summertime low flows and precipitation.

\section{Results}

\section{a. HMM states of summer daily precipitation}

To determine the appropriate number of weather states, Fig. 2 shows the Bayesian information criterion (BIC) for the HMM fit with $H=2, \ldots, 30$ states. Very similar results are seen if the Akaike information criterion (AIC) is used (see Fig. S1 in the online supplement). As the number of states increases, the penalized likelihood metrics continue to monotonically decline until around 20 states, although most of the decline occurs by $H=15$. This suggests that a large number of states are needed to effectively explain the variability in the daily precipitation occurrence data, which is likely due to the heterogeneity of summer precipitation. However, the goal of this study is to diagnose variability in larger-scale summertime rainfall events. We therefore select six states as a manageable number for diagnostic analysis that captures most of the gains in terms of the BIC and AIC metrics. This choice is further supported by the work in Agel et al. (2018, 2019), who also found that six states were appropriate for weather classification in this region. 

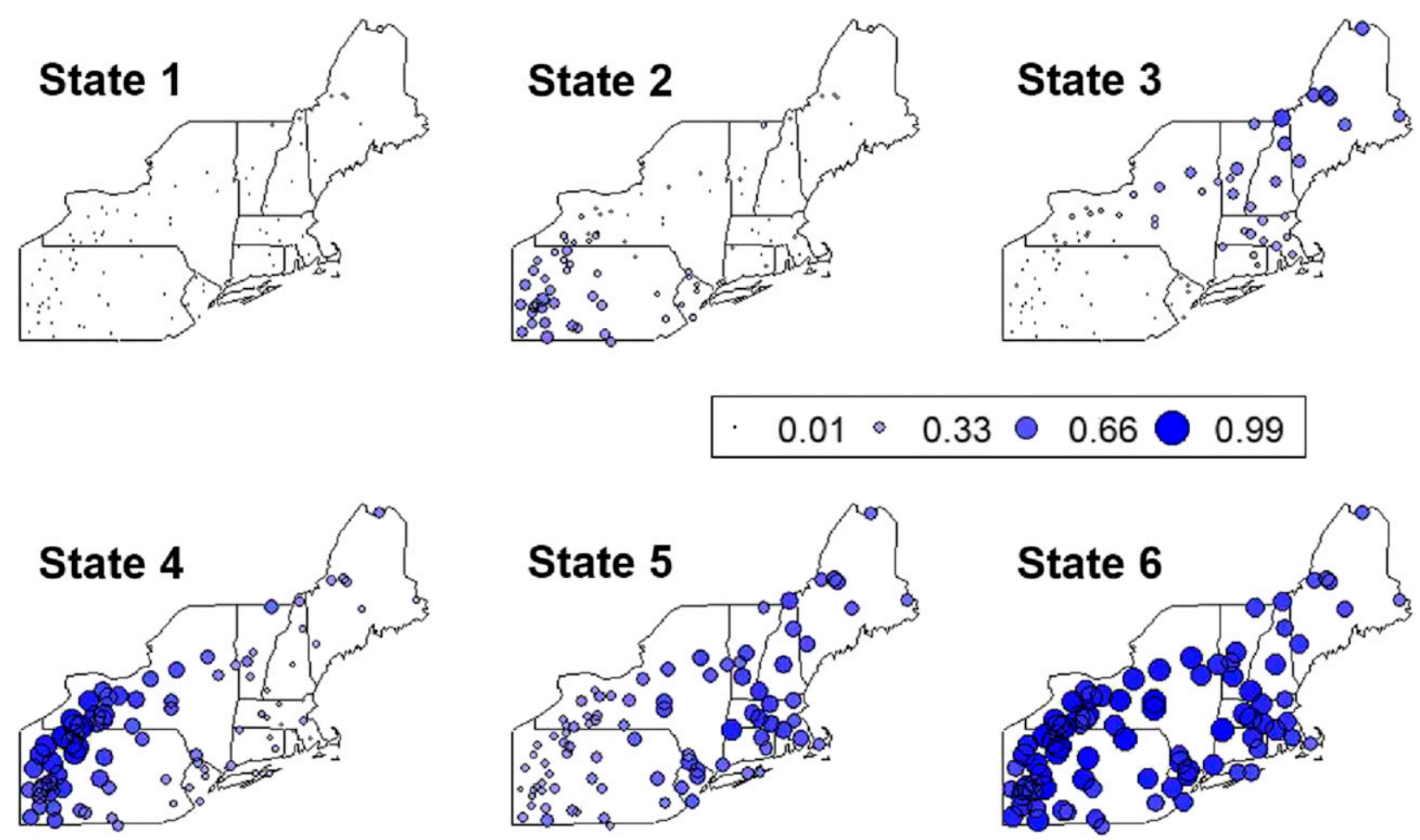

FIG. 3. Map of the probability of precipitation occurrence for each of the six states.

Precipitation occurrence probabilities and the corresponding daily precipitation intensities by state are presented in Figs. 3 and 4, respectively. Table 1 shows the transition probability matrix between states. Rainfall occurrence and intensity show very similar patterns, with less rainfall in states 1-3 and more in states 4-6. State 1 represents relatively dry conditions across the entire northeastern United States (near-zero probability at all stations), and is by far the most frequent and persistent state (Table 1). State 2 shows moderate probabilities of precipitation occurrence along the western part of the Northeast region, with greatest rainfall occurrence and amounts arcing from western Pennsylvania into upstate New York. State 4 shows a very similar pattern, but with much higher occurrence probabilities and intensities, suggesting that state 4 is a more intense version of the same storm track represented in state 2. A similar pattern is seen for states 3 and 5. State 3 is associated with precipitation that is oriented farther along the coast, particularly in northern New England, while state 5 is an intensification of this pattern that also extends farther into southern New England. The transition probability from state 2 to state 4 is higher than the persistence in state 2 , suggesting that most often state 2 represents precipitation at the forward end of a storm track that becomes more intense under state 4 . Similarly, state 5 most often transitions into state 3, suggesting that intense precipitation along a coastal storm track weakens the next day and transitions farther to the north along its path across the Northeast. Overall, states $2-5$ represent a clear east-west dipole in precipitation over the region, and align well with the inland versus coastal daily precipitation patterns and storm tracks identified by Agel et al. (2015). State 6 represents the wettest state across the Northeast. Although state 6 occurs in $15.4 \%$ of the entire record, it accounts for $46.7 \%$ of total summertime precipitation across the Northeast. Taken together, states $4-6$ occur $44.1 \%$ of the time but account for $85.3 \%$ of total precipitation. Finally, we note that the standard deviation of rainfall occurrence probabilities across years is relatively constant (between 0.1 and 0.3 ) for most states and sites, besides very low variances in state 1 (Fig. S2), while the states with greater average intensity generally exhibit more variance in that intensity from year to year (Fig. S3).

Given the results for the BIC and AIC, we also examined precipitation patterns under 15 states, and found that the primary patterns presented in Figs. 3 and 4 do not substantively change (Fig. S4). Almost all of the 15 states exhibit spatial patterns in precipitation occurrence that are strongly associated with one of the six states, although with moderate differences in the precise spatial orientation and probability of occurrences. These results further support the choice of six states as a 

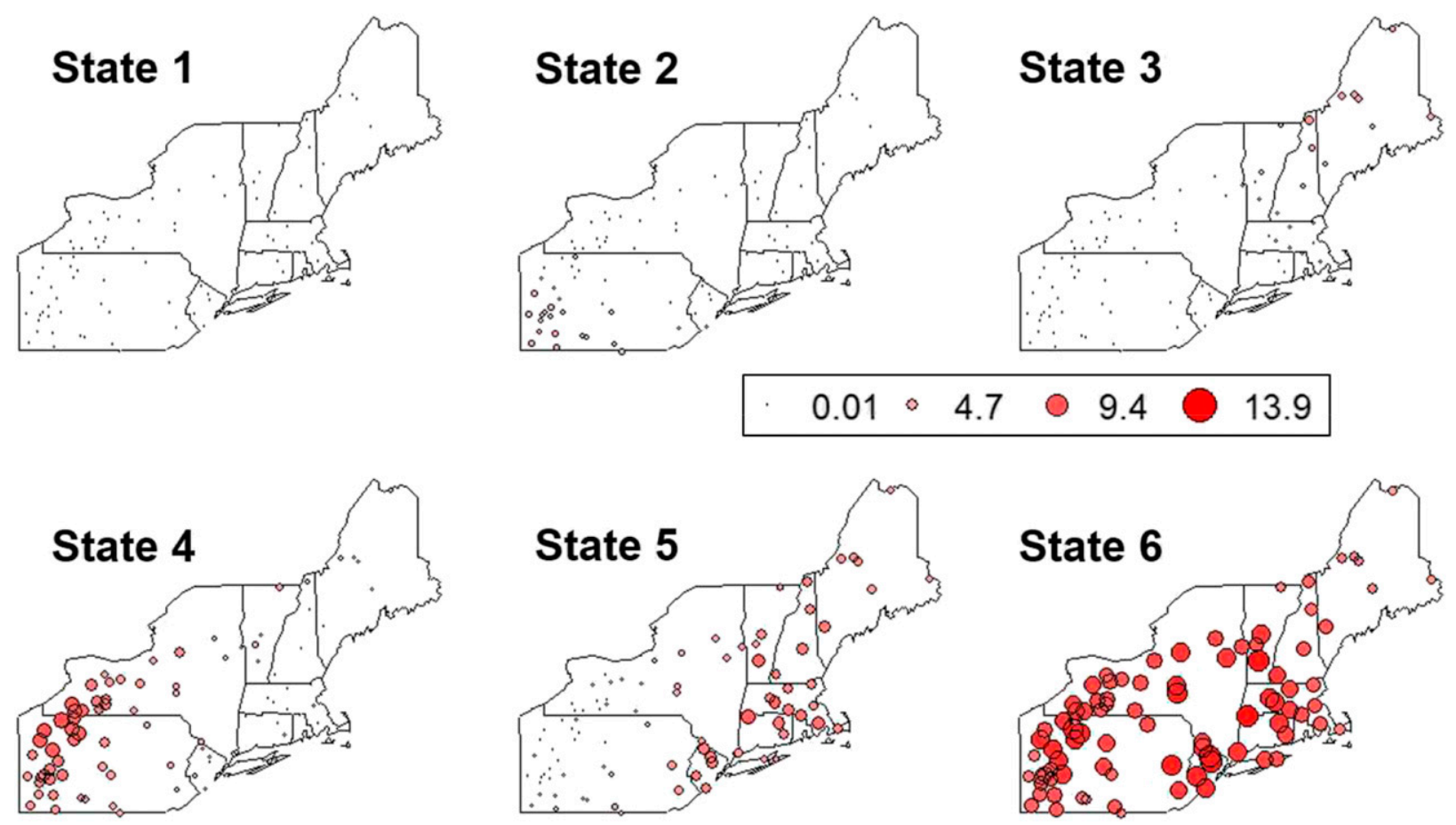

FIG. 4. Map of the average precipitation intensity $(\mathrm{mm})$ for each of the six states.

parsimonious clustering of major precipitation patterns across the Northeast.

Figure 5 shows the total number of state occurrences summed for each calendar day of the summer (1 June31 August) across the 60 -yr record, along with its 14-day moving average. The overall frequencies of states $2-5$ are relatively constant across the summer, although states 2 and 3 show a small increase toward the middle of the season. The frequency of state 1 shows a more pronounced increase in the month of August, while the frequency of state 6 consistently decreases from the latter part of June. This indicates that regional-wide precipitation generally decreases throughout the summer, and is likely associated with the reduction of large-scale extratropical storm systems impacting the Northeast as the jet stream migrates farther north over the season.

Interannual JJA variability in state frequency is presented in Fig. 6, with similar results presented by month in Figs. S5-S7. A trend line is added if the $p$ value of the slope is significant $(<0.05)$ based on a Mann-Kendall test (Kendall 1955; Mann 1945). Most states exhibit no clear trend in the frequency of occurrence over the $60-\mathrm{yr}$ record. However, state 1 exhibits a significant downward trend over the study period that is mirrored by an upward trend in state 6 . The interannual frequencies of these states are also significantly correlated (Pearson $r=-0.59$ ). Further analysis shows that the upward trend in state 6 is primarily from trends during June and
July, while the downward trend in state 1 is most prominent in June (see Figs. S5-S7). Also noteworthy, the variance of the frequency of state 6 in August has become much greater in the most recent twenty years $\left(\sigma^{2}=5.72\right.$ in 1998-2017) compared to the first 20 years $\left(\sigma^{2}=2.42\right.$ in 1958-77). Taken together, these results suggest that largescale rainfall patterns are becoming more frequent in the Northeast, and potentially somewhat more variable, consistent with past work (Frei et al. 2015; Melillo et al. 2014).

\section{b. Weather state frequency during major droughts in the Northeast}

The Northeast has experienced past summertime droughts in the mid-1960s (1963-65), 1991, 1993, 1995,

TABLE 1. Transition probabilities and total counts for the six states in the HMM. The self-transitions are presented in bold.

\begin{tabular}{ccccccc}
\hline & \multicolumn{6}{c}{ To state } \\
\cline { 2 - 7 } & 1 & 2 & 3 & 4 & 5 & 6 \\
\hline From state & & & & & & \\
1 & $\mathbf{0 . 4 7 7}$ & 0.188 & 0.106 & 0.145 & 0.040 & 0.044 \\
2 & 0.154 & $\mathbf{0 . 1 8 3}$ & 0.082 & 0.262 & 0.118 & 0.222 \\
3 & 0.375 & 0.125 & $\mathbf{0 . 2 2 1}$ & 0.115 & 0.087 & 0.077 \\
4 & 0.076 & 0.134 & 0.106 & $\mathbf{0 . 2 0 4}$ & 0.179 & 0.301 \\
5 & 0.203 & 0.112 & 0.256 & 0.103 & $\mathbf{0 . 2 0 9}$ & 0.117 \\
6 & 0.121 & 0.056 & 0.215 & 0.103 & 0.233 & $\mathbf{0 . 2 7 2}$ \\
Total counts & 1456 & 762 & 867 & 853 & 727 & 855 \\
\hline
\end{tabular}



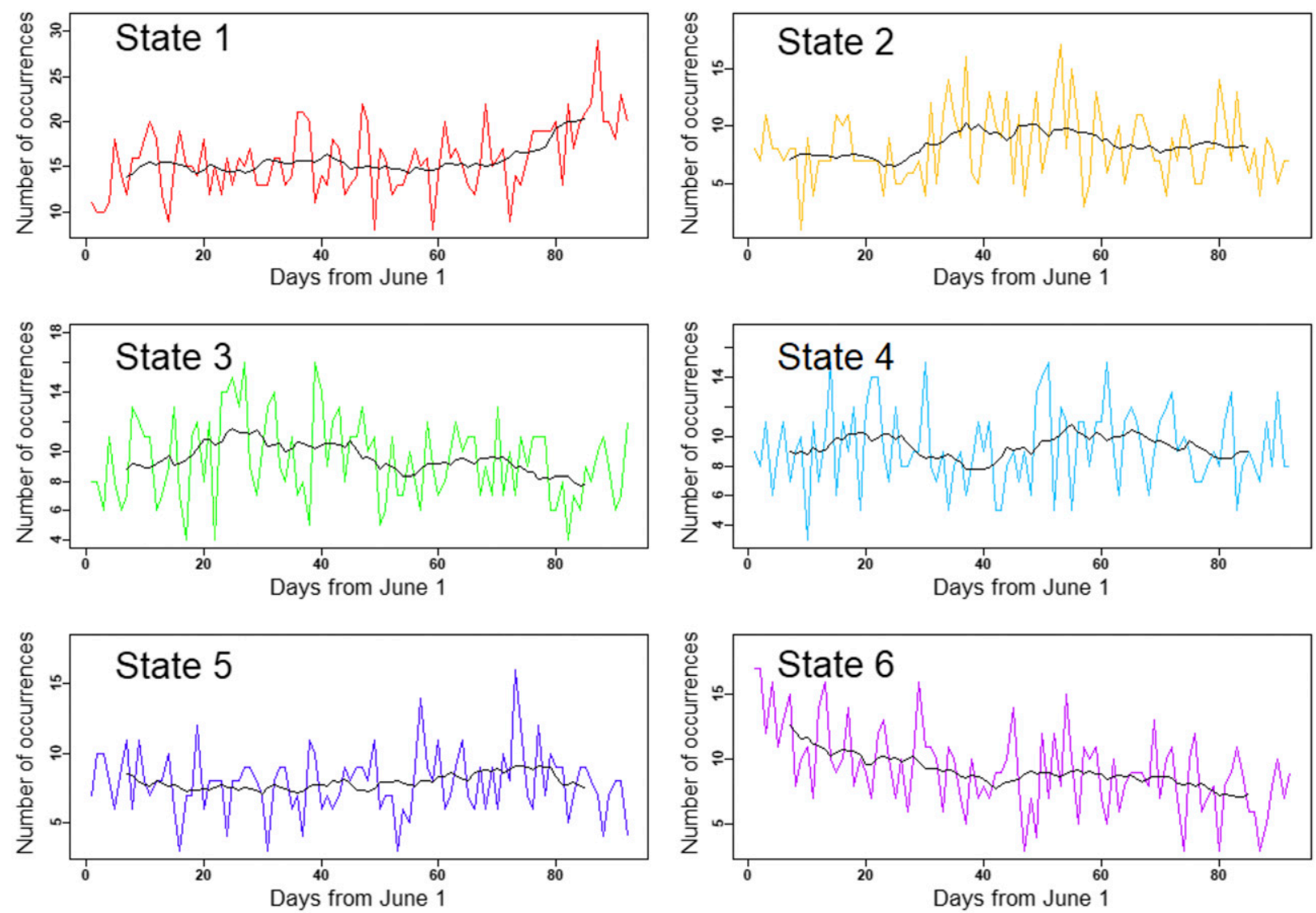

FIG. 5. The number of state occurrences for each calendar day of the year (from 1 Jun to 31 Aug) summed across the 60-yr record, along with its 14-day moving average (black line).

1999, 2002, and 2016 (Andreadis et al. 2005; Coble et al. 2017; Hayhoe et al. 2007; Pederson et al. 2013). Many of these dry periods are reflected in variations in the frequencies of states 1 and 6 , but are also manifest in the frequencies of other states (Fig. 6). To further investigate weather patterns during past droughts, the differences in JJA state frequencies from climatology are shown for the drought years listed above (Fig. 7). The percentage of dry station-days (i.e., percentage of dry days across all days and stations) for each drought year is also shown. Overall, drought years are dominated by an increased frequency of states 1-3 and decreased frequency of states 4-6. However, each drought can exhibit its own flavor of state frequencies that dictates the depth and spatial distribution of drought conditions. For instance, droughts in 1991, 1995, and 2002 were dominated by an increase in state 1 occurrences and a decline in the occurrence of the states 4,5 , or 6 , which are the wettest states across the Northeast. Accordingly, these droughts exhibited a high percentage of dry station-days (on average, 1.75 standard deviations above the long-term mean). The 1960s drought exhibited a much different pattern. In 1963, the frequencies of states 1, 5, and 6 were near average, while states 3 and 4 were anomalously frequent and absent, respectively. This suggests that 1963 was dominated by light rainfall over the northeast portion of the region and very few heavy rainfall events in the west. 1964 showed an even larger increase in state 3 occurrences, but exhibited a significant decline in both states 1 and 6. Both 1963 and 1964 exhibited a somewhat lower percentage of dry station-days (on average, 0.65 standard deviations above the long-term mean), at least compared to 1991, 1995, and 2002. In 1965, occurrences of both states 1 and 2 were somewhat above average, while state 6 was noticeably absent. Similar to 1964, state 3 in 1999 occurred very frequently, primarily at the expense of states 4-6. Finally, 1993 and 2016 showed the least anomalous state frequencies, in part because these droughts did not extend across the entire summer season. The drought in 1993 did not begin until the middle of the summer, while August rainfall linked to higher rates of state 4 began to alleviate drought conditions in 2016. In addition, for the 2016 event, hydrologic drought conditions were enhanced because of anomalously higher 

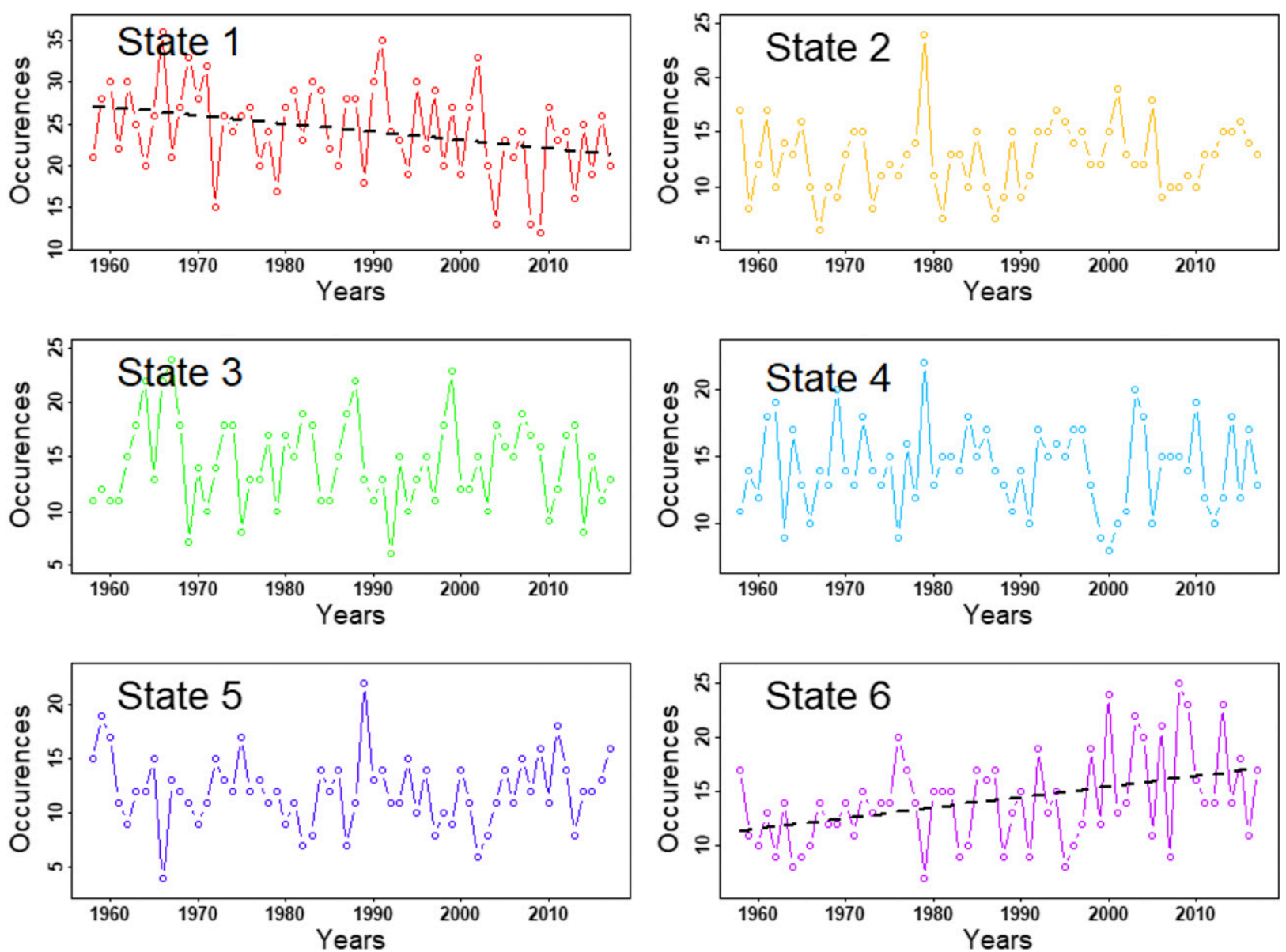

FIG. 6. The number of state occurrences for each summer (JJA). The trend line is presented if a Mann-Kendall test has a $p$ value $<0.05$.

temperatures and extremely low snowfall throughout the 2015/16 snow season (Sweet et al. 2017).

While the results in Fig. 7 suggest that summer drought conditions in the Northeast can arise due to a multitude of precipitation patterns across the region, two primary patterns stand out. The first is an increase of the frequency of state 1 and a decline in states 4-6 (1991, $1995,2002)$, and is associated with widespread declines in precipitation across the entire Northeast. The second is better described as a shift to more frequent occurrences of light precipitation at the expense of heavy precipitation events $(1963-65,1999)$, particularly more frequent occurrences of state 3 , which suggest that storms are being diverted farther east along the coastline and are more often impacting northeast New England than the central portion of the Northeast.

\section{c. Atmospheric circulation and antecedent SSTAs}

Figure 8 shows composites of 850 -hPa geopotential height and IVT anomalies averaged for all days in states $1-6$. These composites are extremely similar if based on
ERA-Interim data over the shorter period between 1979 and 2017 (not shown). During state 1, the northeastern United States is situated directly under the eastern part of a large anticyclonic circulation centered on Pennsylvania, with descending air and anomalous northerly flow suppressing precipitation across the entire region. During state 2, the low-level anticyclone is weaker and shifted to the east. Southerly flow along the western edge of the low-level high delivers moderate amounts of precipitation to the Ohio River basin, with small rainfall anomalies entering the western portion of the Northeast. During state 4, the low-level high along the eastern U.S. coast weakens from that in state 2 , but a strong low pressure system over the Great Lakes strengthens the southerly flow from the Gulf of Mexico and shifts it farther eastward, increasing precipitation across the Ohio River basin into western Pennsylvania and New York. The high transition probability from state 2 to state 4 (see Table 1) suggests that states 2 and 4 represent the evolution of the west-to-east extratropical storm track that traverses the northern portion of the 

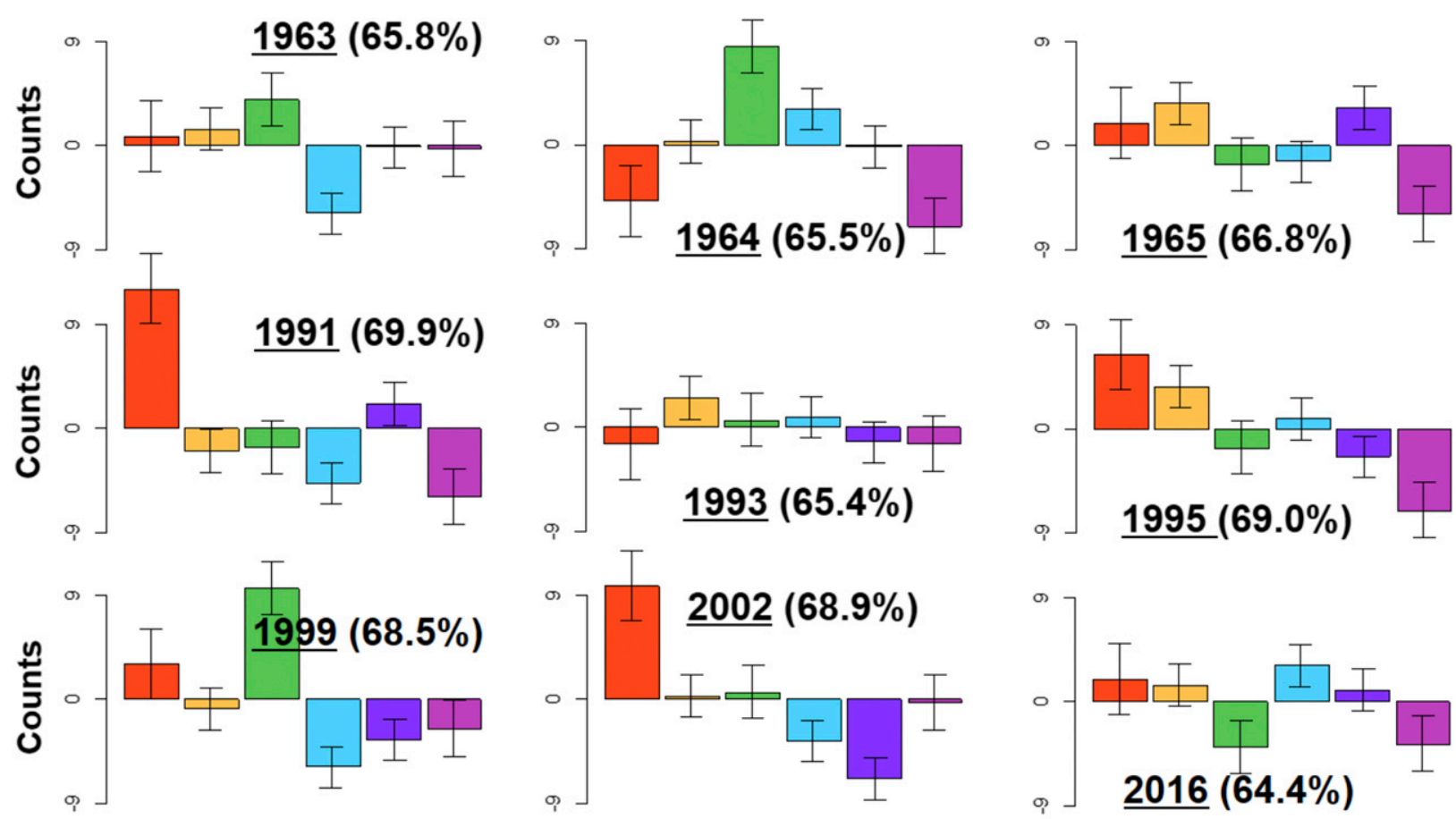

\section{State 1 -State 2 State 3 - State 4 - State 5 - State 6}

FIG. 7. The number of state occurrences in JJA for drought years in the Northeast, shown as a difference from the climatological average number of state occurrences and \pm 1 standard deviations (whiskers) for each state. The percentage of dry station-days across all JJA days and stations for each year is presented in parentheses. The mean and standard deviation of dry station-days across $1958-2017$ is $62.9 \%$ and $3.99 \%$, respectively.

Northeast, similar to that identified by Agel et al. (2015). In addition, it is most common for state 4 to transition into state 6 , where the low-level low pressure system is situated directly over the Northeast and rainfall is widespread. Therefore, state 6 also seems most often associated with this west-to-east storm track, and represents the time when such storms are having their greatest impact on precipitation across the Northeast. However, it is important to note that state 6 also includes other events that are unrelated to this extratropical storm track, for instance tropical storms and hurricanes (not shown). During state 3, a low pressure system is situated over northeastern New England, enhancing convergence and precipitation in that region, while a high-pressure center over the Ohio River basin suppresses precipitation farther to the west. The low pressure system is elongated and located farther to the southwest during state 5 , bringing heavier rains across the coastal region. The positive transition probability from state 5 to state 3 suggests that the storm track for this low pressure system often migrates northeast along the coast, consistent with the coastal storm track identified in Agel et al. (2015). Taken together, Fig. 8 and the transition probabilities in Table 1 suggest that the six weather states represent two major storm tracks: 1) an extratropical track along the northern portion of the Northeast (states 2, 4, and 6), and 2) a coastal track that primarily impacts rainfall in the eastern portion of the region (states 3,5). By virtue of the HMM algorithm, however, other events unrelated to these tracks are also clustered into these states.

To determine whether the synoptic-scale circulation patterns for each weather state are forced by SSTAs, Fig. 9 presents composites of detrended May SSTAs for the summers with the 10 lowest and highest frequencies of each state. Composites of 300-hPa geopotential heights for all days in those same summers are also shown. Several insights emerge from this figure. First, for state 1, the SSTA pattern is asymmetric across low and high occurrence years. A significant springtime cold anomaly in the eastern Caribbean and north tropical Atlantic Ocean precedes summers with very few state 1 occurrences. There are also positive (albeit statistically insignificant) SSTAs off the eastern coast of the United States and a cold anomaly south of Greenland, consistent with a positive NAT pattern. Furthermore, there is a clear upper-level wave train across North America with a trough/ridge pattern straddling the Northeast and an anomalous trough over the subtropical Atlantic. However, no significant SSTAs precede summers with a large number of state 1 occurrences, while an upper-level 

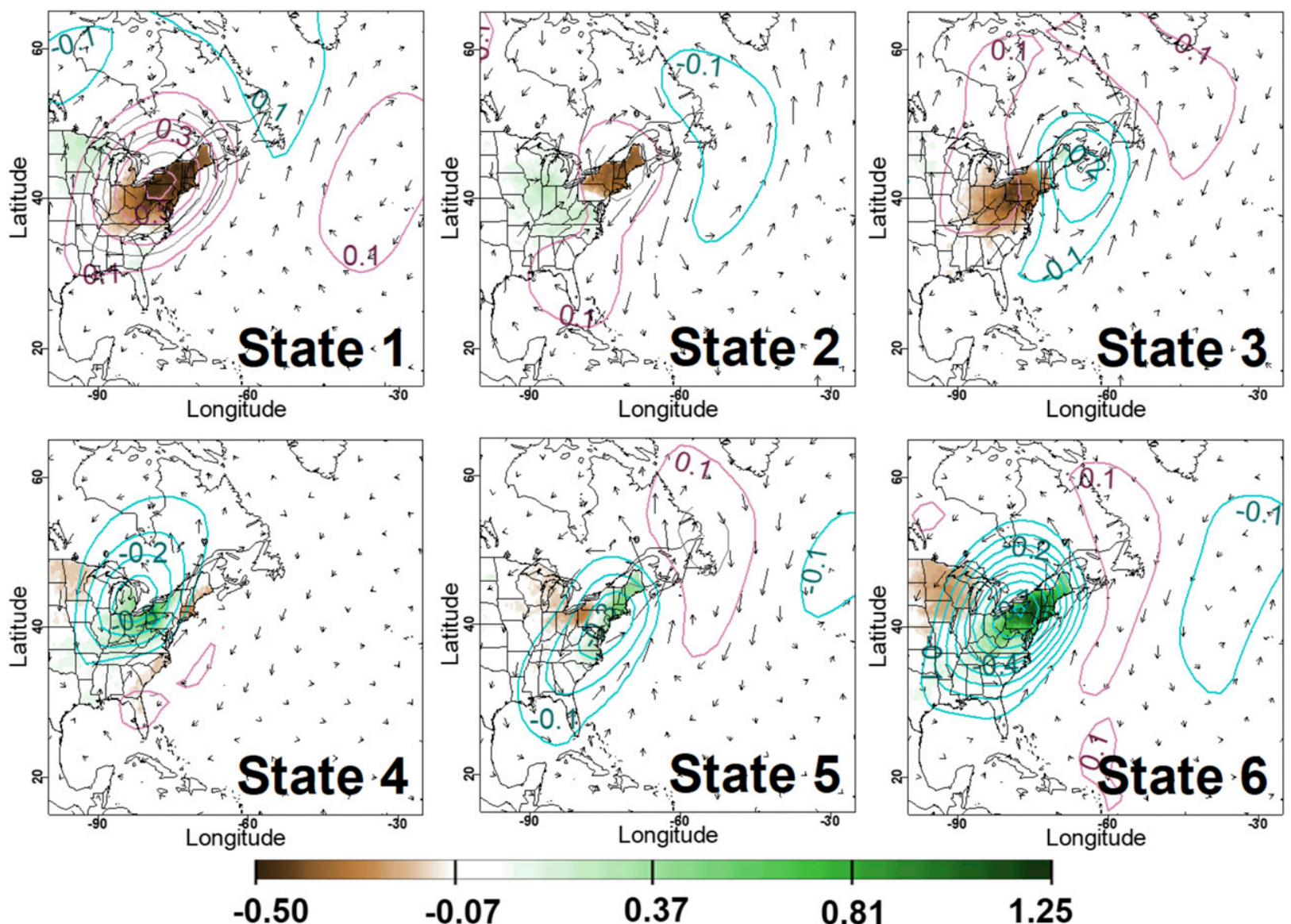

FIG. 8. Composite analysis for a given weather state, including rainfall standardized anomalies over the contiguous United States, positive (red) and negative (cyan) $850-\mathrm{hPa}$ geopotential height standardized anomalies (contours), and IVT standardized anomalies (arrows). Contour interval is 0.1 standard deviations.

ridge over much of the Northeast and southeastern Canada appears inside an extratropical wave packet without clear links to the subtropics or tropics. This suggests that severe droughts over the Northeast, during which state 1 events are frequent, are not well predicted by antecedent SSTA conditions and tropical or subtropical forcing. Rather, these events appear linked to a localized and persistent ridge that occurs due to internal atmospheric variability, in line with the argument of Seager et al. (2012). However, the absence of drought conditions (i.e., few state 1 occurrences) appears related to antecedent SSTAs in the tropical North Atlantic that may contribute to a larger-scale wave train that enhances divergence aloft near the northeastern United States.

In summers with very few state 6 occurrences, significant positive May SSTAs emerge in a similar location to those for low state 1 occurrences (eastern Caribbean and north tropical Atlantic). When state 6 occurs frequently, a cold springtime SSTA pattern is observed that resembles the pattern for years with few state 1 occurrences, although the SSTAs are more squarely situated in the
Caribbean Sea. There is also a warm anomaly southeast of Newfoundland, which presents weakly in the composites for low state 1 occurrences. The upper level height anomalies during summers with the greatest and fewest state 6 occurrences are very similar to those for state 1 , albeit with the patterns reversed. However, unlike state 1, the SSTAs for state 6 are somewhat more symmetric across the lowestand highest-frequency years.

For summers with a high frequency of state 5 , SSTAs are similar to those associated with low state 1 frequencies, although the lobe in the tropical Atlantic is situated farther to the east. In addition, central and northern Atlantic lobes of SSTAs (reflective of a positive NAT event) are statistically significant. When state 5 is less frequent, the Atlantic SSTA signal weakens, but there is a more prominent dipole in the Pacific with a positive nearequatorial SSTA pattern reminiscent of a central Pacific ENSO event (Kao and Yu 2009). There also appears to be a wave train emerging from the equatorial Pacific, with a ridge located to the west of the Northeast that may suppress precipitation under its eastern flank. 

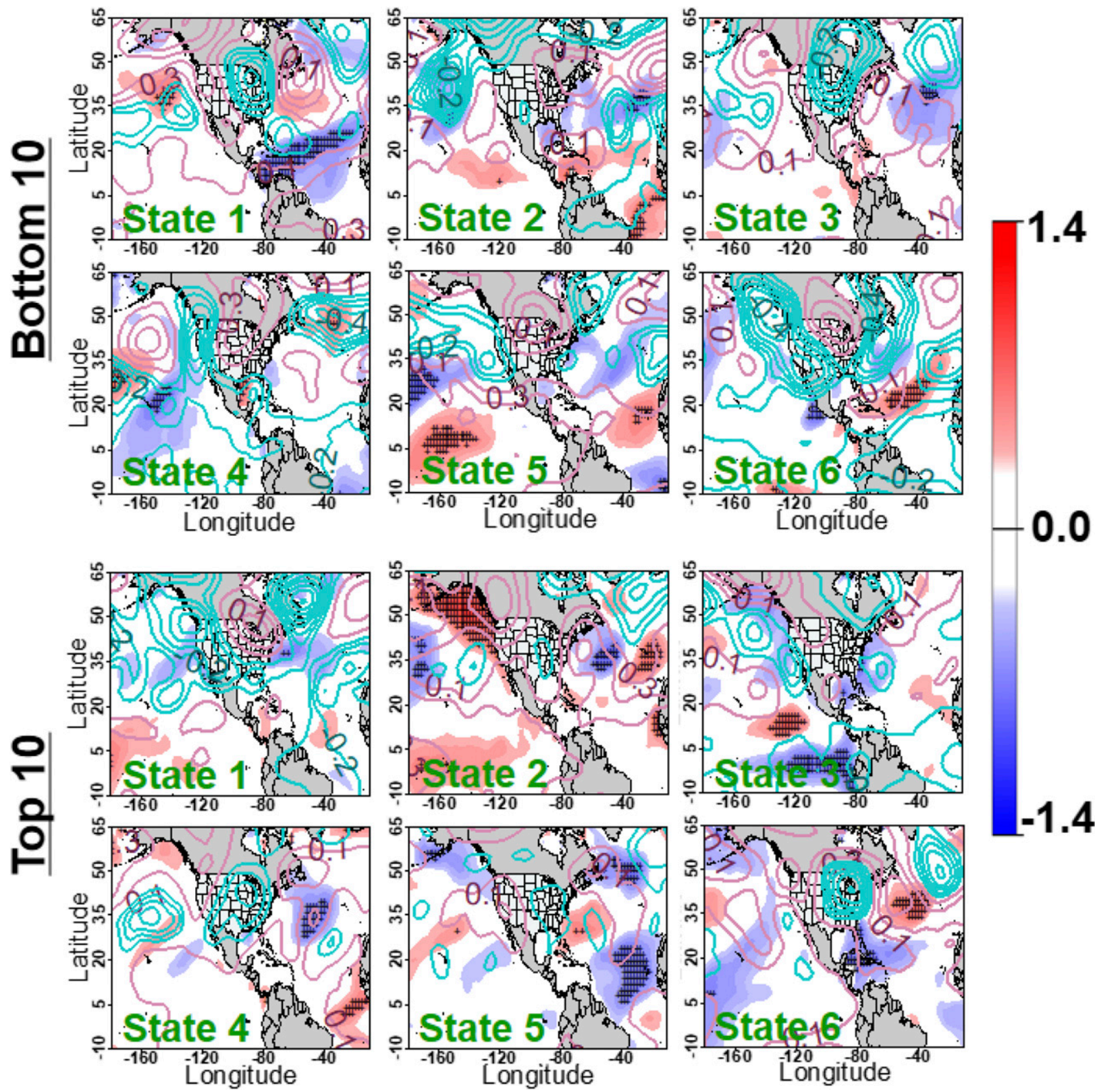

FIG. 9. Composite maps of detrended May SSTAs for summers with the 10 lowest and highest frequencies of each state. Statistically significant SSTAs are shown with stippling. Composites of positive (red) and negative (cyan) 300-hPa geopotential height standardized anomalies (contours) for all days in each set of 10 years are also shown. Contour interval is 0.1 standard deviations.

We note that when considering the entire domain over both Pacific and Atlantic sectors, the results above are not field significant at the 0.05 level using a false discovery rate approach (Wilks 2006). This may indicate that the SSTA patterns for states 1, 5, and 6 are not distinguishable from random noise. However, if the domain is reduced to individual ocean subbasins, these signals become field significant. Coupled with their consistency with climate model-based results (discussed later), this suggests that the number of years of data may be too short or the strength of the signal not strong enough to detect field significance over the larger Pacific-Atlantic domain.

Most of the other states have less clear associations with antecedent SSTAs, with a few exceptions. High frequencies of state 2 appear strongly linked to warm SSTAs in the Gulf of Alaska, while high frequencies of state 3 are associated with an eastern Pacific La Niña event. Low frequencies of state 4 may be weakly associated with a negative PDO. Overall though, these patterns are less distinct than those for states 1,5 , and 6 , 

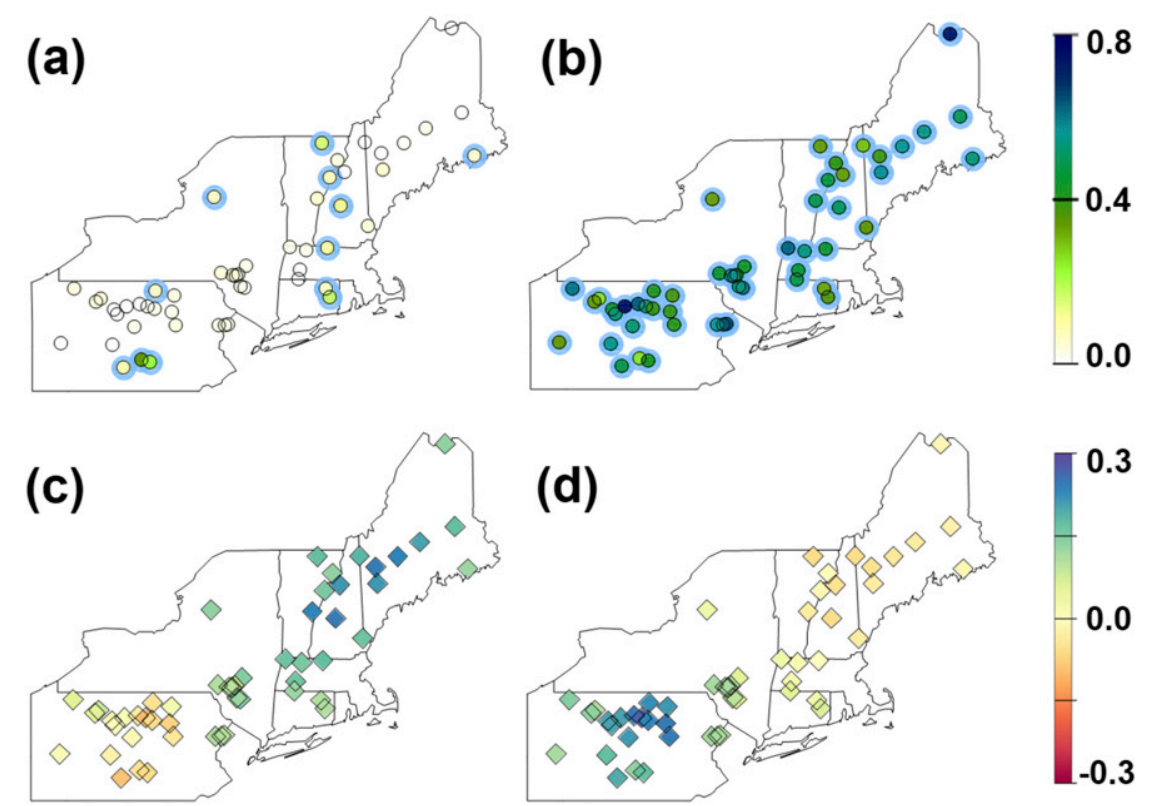

FIG. 10. (a) The $R^{2}$ between 7-day low flows and May basin rainfall, and (b) $R^{2}$ between residuals obtained in (a) and JJA basin rainfall. Statistical significance at the $95 \%$ level is shown by light blue shading. Loadings of the (c) first and (d) second rotated EOFs for the residuals from (a).

and besides state 3 , have less association with tropical and subtropical SSTAs that are thought to provide the strongest boundary forcing for seasonal forecasts (Trenberth et al. 1998). Taken together, the primary results suggest that warm waters in the Caribbean Sea and north tropical Atlantic tend to reduce the likelihood of regionally widespread precipitation events across the Northeast, while cold waters in this region reduce the likelihood of widespread rainfall deficits. The asymmetry in the SSTA patterns across states indicates that predicting major droughts (i.e., high frequencies of state 1) with antecedent SSTAs may not be possible, but there may be potential to predict the likelihood of wet conditions (i.e., high and low frequencies of states 5 and 6).

\section{d. Revisiting seasonal forecasts of low flows in the northeast United States}

Finally, we reexamine the predictability of summer low flows based on spring SSTAs that has been argued in previous work (Ahn et al. 2017; Steinschneider and Brown 2011, 2012a,b). First, the effects of hydrologic memory are controlled by separately regressing JJA SDLFs against May streamflow, April-May rainfall, and May rainfall for each basin. May rainfall is the best antecedent explanatory variable of SDLFs across the region, but is still limited in its explanatory power (Fig. 10a; median and maximum values of regression $R^{2}$ are 0.08 and 0.23 , respectively). This suggests that SDLFs in this region are not well explained by antecedent conditions, at least as measured by streamflow and rainfall proxies. Rather, SDLFs are fairly well explained by rainfall that falls in the concurrent JJA season (Fig. 10b). The spatial variability of the residuals of the regression of SDLFs against May rainfall is summarized using two REOFs. The first REOF emphasizes SDLFs in New England, particularly in Vermont, New Hampshire, and Maine (Fig. 10c), while the second REOF emphasizes SDLF variability in Pennsylvania (Fig. 10d).

Figure 11 shows composites of detrended May SSTAs for the summers with the highest and lowest values for the two RPCs. When the effects of antecedent precipitation are removed, the tripolar NAT pattern in the Atlantic still emerges for both RPCs in years when SDLFs are anomalously high, indicating this signal is not the result of hydrologic memory alone. For RPC1, which emphasizes SDLFs in New England, the SSTA lobe in the central Atlantic is strong and situated just southeast of Newfoundland, while the southern lobe of SSTAs is located squarely in the Caribbean Sea (Fig. 11b). This pattern is most similar to that for high frequencies of weather state 6 . The SSTAs preceding large values of RPC2 (which emphasizes SDLFs in Pennsylvania) have a weaker central Atlantic lobe, and the southern lobe of SSTAs is spread more broadly across the tropical North Atlantic (Fig. 11d). This pattern appears to be better described as a mix of the SSTAs patterns under high frequencies for weather states 5 and 6 .

Antecedent SSTAs in summers with low SDLFs for both RPC1 and RPC2 are significantly different and 

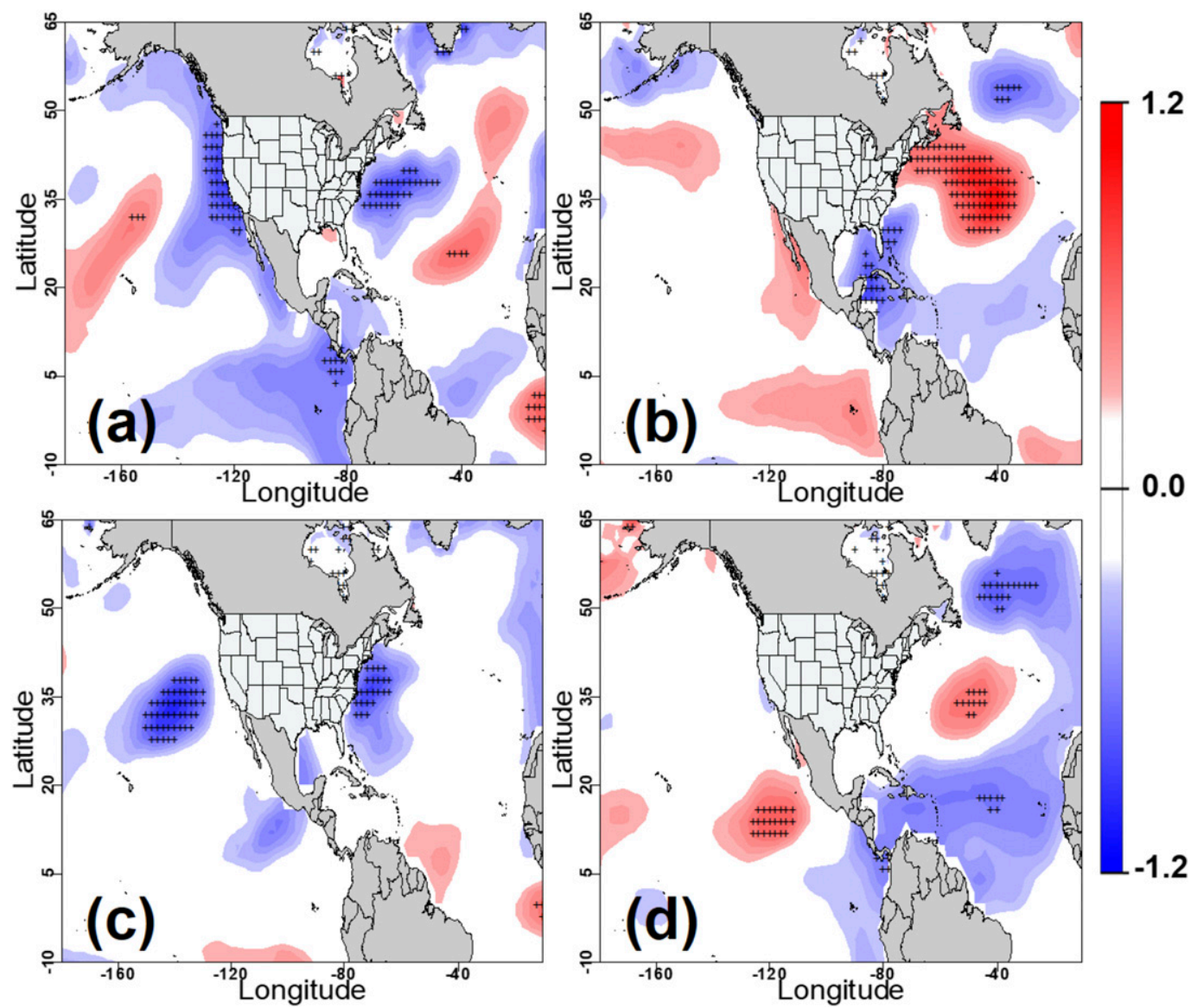

FIG. 11. Composite maps of detrended May SSTAs for summers with the 10 lowest and highest values of the rotated PCs of residuals between SDLFs and May precipitation. The (a) lowest and (b) highest 10 years of the first RPC. The (c) lowest and (d) highest 10 years of the second RPC. Statistically significant SSTAs are shown with stippling.

asymmetric compared to those for summers with high SDLFs. For RPC1, there is a cold lobe of SSTAs in the western Atlantic and a warm lobe in the south-central Atlantic (Fig. 11a). These lobes are of opposite sign to those for summers with large RPC1 values (Fig. 11b), but their locations are shifted, particularly for the southern lobe. The pattern in Fig. 11a most resembles SSTAs that precede low frequencies of state 6 . Differences between high and low SDLF years are even more drastic for RPC2, which shows no clear NAT pattern at all (Fig. 11c). Rather, cold SSTAs are localized along the eastern and western coastlines of the United States. This pattern weakly resembles that for summers with a high frequency of state 1 occurrences, although the SSTAs are insignificant for the weather state composites.

\section{Discussion}

The composite analyses for SDLFs suggest that the previously identified NAT forecast signal for low flows in the Northeast shares many of the same antecedent
SSTA patterns as key weather states in the region. This agreement holds after removing the effects of antecedent moisture on the SDLF values, indicating that hydrologic memory does not significantly account for the NAT forecast signal. Rather, the occurrence of high SDLF values across the Northeast region appears primarily driven by enhanced summertime rainfall (Fig. 10b). Both higher SDLFs and rainfall values are associated with more frequent occurrences of states 5 and 6 and a reduction in state 1 frequency, which tend to co-occur with cooler spring waters in the tropical North Atlantic and Caribbean Sea, as well as warmer waters off the east coast of the United States. These results support previous empirical studies that have shown some ability to forecast low-flow events in the Northeast using measures of antecedent climate over the Atlantic basin (Ahn et al. 2017; Armstrong et al. 2014; Berton et al. 2017; Coleman and Budikova 2013; Steinschneider and Brown 2011, 2012b). They also agree with past modeling work that has shown that cooler waters in the tropical North Atlantic and Caribbean Sea can enhance summer moisture advection 
into the eastern United States (Sutton and Hodson 2005). The cool Caribbean and tropical North Atlantic waters and the Rossby wave train observed during summers with low frequencies of state 1 and high frequencies of state 6 (see Fig. 9) resemble ocean-atmosphere relationships for the summertime east Atlantic pattern recently identified by Wulff et al. (2017). That study used the European Centre for Medium-Range Weather Forecasts Integrated Forecasting System (Dee et al. 2011) to show that the JJA wave train is forced by anomalies in SSTAs initialized in May. This modeling result is supported empirically by Ossó et al. (2018), who used lagged regression to show that the summer east Atlantic pattern and the associated wave train is predictable based on spring SSTAs that resemble the NAT. The wave train is also very similar to that observed when the western ridge of the NASH shifts anomalously to the southwest of its climatological position (Doering and Steinschneider 2018). Under that orientation, Doering and Steinschneider (2018) found that the NASH strongly enhances moisture advection and precipitation in the Southeast, but rainfall increases extend northward to the southern portion of the Northeast. They also found spring SST conditions unique to the southwest NASH orientation that strongly resemble those of enhanced SDLFs for REOF2 (Fig. 11d). Coupled with the results of these past studies, the work presented here suggests that there is some potential for seasonal forecasts of anomalously high summer precipitation and SDLFs in parts of the Northeast region based on SST conditions in the North Atlantic Ocean, which force teleconnections linked to perturbations in the NASH and a wave train that extends across the Pacific and Atlantic sectors.

Conversely, the occurrence of low SDLFs across the Northeast is less clearly related to antecedent SSTAs, particularly those in subtropical and equatorial regions (Figs. 11a,c). No clear NAT forecasting signal emerges for these extreme low-flow events. This asymmetry mirrors that for weather states associated with dry conditions. Summers with the most frequent occurrences of weather state 1 were also unrelated to any significant antecedent SSTAs in the subtropics and tropics. These results generally suggest that drought years dominated by a summertime ridge over the Northeast (e.g., 1991, 1995, 2002, see Fig. 7) are not well predicted by SST boundary forcing, but rather emerge due to internal atmospheric variability, as argued by Seager et al. (2012). Consequently, forecasts of SDLFs in such years based on SSTAs would also be unreliable.

The main objective of this work was focused on helping to resolve past discrepancies between empirical and modeled assessments of summer rainfall and lowflow predictability in the Northeast based on springtime Atlantic climate. However, we also identified some teleconnections in the Pacific, for example, El Niño conditions prior to summers with infrequent state 5 occurrences and La Niña conditions prior to frequent state 3 occurrences. These results, in particular for reduced state 5 occurrences and coastal rainfall, are consistent with other studies that have found summer drying along the eastern U.S. coastline following spring El Niño events (Bosilovich 2013). Therefore, SSTAs in the equatorial Pacific may also prove useful for the prediction of summer weather state occurrences and associated precipitation.

\section{Conclusions}

This study contributes an assessment of the intra- and interseasonal variability of summer precipitation patterns across a network of rainfall stations in the Northeast United States, as well as their predictability and relationship to patterns of low streamflows across the region. Using a hidden Markov model, six weather states were identified that describe the temporal variability of inland and coastal patterns of rainfall that vary in intensity. The frequency of very dry (state 1) conditions showed significant declines throughout the 60-yr record, particularly in the earlier part of the summer. Concurrently, very wet conditions (state 6) exhibited upward trends in frequency across the period of record, also in the early months of the summer season. The weather states were used to better understand precipitation patterns during major historical droughts, and were shown to vary considerably across drought events, suggesting that different climatic mechanisms can lead to dry summer conditions over the Northeast region. Those mechanisms were explored using atmospheric composites, which revealed distinct patterns of atmospheric flow associated with a blocking ridge during very dry conditions and two sets of storm tracks associated with a shift between inland and coastal rainfall.

Last, we evaluated the relationship between springtime SSTAs and the frequency of weather states and patterns of low flows across the Northeast, in an effort to resolve discrepancies between past empirical and modeling studies. We found an asymmetric relationship between weather states and antecedent SSTAs, in particular those in the tropical and subtropical Atlantic, that suggests that dry conditions in the Northeast associated with a blocking ridge are poorly related to boundary forcing, but wet conditions may be predictable based on a springtime NAT signal. These relationships were similar for low flows across the Northeast, and help reconcile the lack of drought predictability found by Seager et al. (2012) and the empirical predictability identified by several authors (Ahn et al. 2017; Armstrong et al. 2014; Berton 
et al. 2017; Coleman and Budikova 2013; Steinschneider and Brown 2011, 2012b).

The results of this work suggest that summertime forecasts of rainfall and streamflow over the Northeast may be possible if carefully tailored for specific Atlantic basin conditions. Future work is needed to develop a model to that can produce such forecasts. For instance, a nonhomogeneous HMM (NHMM) (Cioffi et al. 2017; Fu et al. 2013) provides one strategy that maintains the weather state framework presented in this work. However, any modeling framework would need to address the inherent nonlinearity in the underlying teleconnections, suggesting that a multinomial regression on SSTAs may not be appropriate. Recent machine learning algorithms (Le et al. 2017) may prove more effective at capturing the underlying asymmetry.

Many studies have reported that future anthropogenicinduced changes on hydroclimate in the Northeast will likely increase the frequency of heavy rainfall events and summer water deficits by the end of the twenty-first century (Kolb et al. 2016; Ning et al. 2015; Wolfe et al. 2018). Many of these arguments are based on thermodynamic changes to the climate, that is, increasing temperatures and a greater water holding capacity of the atmosphere. In this work, we observed trends in dynamical components of circulation that may be contributing to long-term climate trends, including observed changes to extreme events (Frei et al. 2015; Huang et al. 2018). More research is needed to explore the degree to which trends in extreme events are linked to trends in circulation regimes, and to determine the implications with regard to the occurrence of future extremes based on projected shifts in circulation. In addition, trends in weather states may be useful to inform forecast-informed adaptive management of agricultural and water systems that could potentially offset the impacts of thermodynamic climate change. Critical to this approach is an understanding of how climate change will impact ocean circulation and resulting teleconnections (Chen et al. 2017; Ruprich-Robert et al. 2017; Steinman et al. 2015). Therefore, future work should not only investigate the strength of out-of-sample forecasts developed using the teleconnection patterns identified here, but also their stability under long-term climate change.

Acknowledgments. This work was supported by the USDA National Institute of Food and Agriculture, Hatch project 1014292.

\section{REFERENCES}

Agel, L., M. Barlow, J.-H. Qian, F. Colby, E. Douglas, and T. Eichler, 2015: Climatology of daily precipitation and extreme precipitation events in the northeast United States.
J. Hydrometeor., 16, 2537-2557, https://doi.org/10.1175/ JHM-D-14-0147.1.

,-- S. B. Feldstein, and W. J. Gutowski, 2018: Identification of large-scale meteorological patterns associated with extreme precipitation in the US northeast. Climate Dyn., 50, 1819-1839, https://doi.org/10.1007/s00382-017-3724-8.

,,-- F. Colby, H. Binder, J. L. Catto, A. Hoell, and J. Cohen, 2019: Dynamical analysis of extreme precipitation in the US northeast based on large-scale meteorological patterns. Climate Dyn., 52, 1739-1760, https://doi.org/10.1007/s00382-018-4223-2.

Ahn, K.-H., R. Palmer, and S. Steinschneider, 2017: A hierarchical Bayesian model for regionalized seasonal forecasts: Application to low flows in the northeastern United States. Water Resour. Res., 53, 503-521, https://doi.org/10.1002/2016WR019605.

Andreadis, K. M., E. A. Clark, A. W. Wood, A. F. Hamlet, and D. P. Lettenmaier, 2005: Twentieth-century drought in the conterminous United States. J. Hydrometeor., 6, 985-1001, https://doi.org/10.1175/JHM450.1.

Armstrong, W. H., M. J. Collins, and N. P. Snyder, 2014: Hydroclimatic flood trends in the northeastern United States and linkages with large-scale atmospheric circulation patterns. Hydrol. Sci. J., 59, 1636-1655, https://doi.org/10.1080/02626667.2013.862339.

Berton, R., C. T. Driscoll, and J. F. Adamowski, 2017: The nearterm prediction of drought and flooding conditions in the northeastern United States based on extreme phases of AMO and NAO. J. Hydrol., 553, 130-141, https://doi.org/10.1016/ j.jhydrol.2017.07.041.

Bosilovich, M. G., 2013: Regional climate and variability of NASA MERRA and recent reanalyses: U.S. summertime precipitation and temperature. J. Appl. Meteor. Climatol., 52, 1939-1951, https://doi.org/10.1175/JAMC-D-12-0291.1.

Carter, E., and S. Steinschneider, 2018: Hydroclimatological drivers of extreme floods on Lake Ontario. Water Resour. Res. 54, 4461-4478, https://doi.org/10.1029/2018WR022908.

Celeux, G., and G. Govaert, 1992: A classification EM algorithm for clustering and two stochastic versions. Comput. Stat. Data Anal., 14, 315-332, https://doi.org/10.1016/0167-9473(92)90042-E.

Chen, C., M. A. Cane, A. T. Wittenberg, and D. Chen, 2017: ENSO in the CMIP5 simulations: Life cycles, diversity, and responses to climate change. J. Climate, 30, 775-801, https://doi.org/ 10.1175/JCLI-D-15-0901.1.

Chen, M., W. Shi, P. Xie, V. B. Silva, V. E. Kousky, R. W. Higgins, and J. E. Janowiak, 2008: Assessing objective techniques for gauge-based analyses of global daily precipitation. J. Geophys. Res., 113, D04110, https://doi.org/10.1029/2007JD009132.

Cioffi, F., F. Conticello, U. Lall, L. Marotta, and V. Telesca, 2017: Large scale climate and rainfall seasonality in a Mediterranean Area: Insights from a non-homogeneous Markov model applied to the Agro-Pontino plain. Hydrol. Processes, 31, 668-686, https://doi.org/10.1002/hyp.11061.

Coble, A. P., and Coauthors, 2017: Are northeastern US forests vulnerable to extreme drought? Ecol. Process., 6, 34, https:// doi.org/10.1186/s13717-017-0100-x.

Coleman, J. S., and D. Budikova, 2013: Eastern U.S. summer streamflow during extreme phases of the North Atlantic oscillation. J. Geophys. Res. Atmos., 118, 4181-4193, https:// doi.org/10.1002/jgrd.50326.

Dee, D. P., and Coauthors, 2011: The ERA-Interim reanalysis: Configuration and performance of the data assimilation system. Quart. J. Roy. Meteor. Soc., 137, 553-597, https://doi.org/ 10.1002/qj.828.

Doering, K., and S. Steinschneider, 2018: Summer co-variability of surface climate for renewable energy across the contiguous 
United States: Role of the North Atlantic subtropical high. J. Appl. Meteor. Climatol., 57, 2749-2768, https://doi.org/ 10.1175/JAMC-D-18-0088.1.

Efron, B., 1992: Bootstrap methods: Another look at the jackknife. Breakthroughs in Statistics, Springer, 569-593.

Falcone, J. A., D. M. Carlisle, D. M. Wolock, and M. R. Meador, 2010: GAGES: A stream gage database for evaluating natural and altered flow conditions in the conterminous United States. Ecology, 91, 621-621, https://doi.org/10.1890/09-0889.1.

Frei, A., K. E. Kunkel, and A. Matonse, 2015: The seasonal nature of extreme hydrological events in the northeastern United States. J. Hydrometeor., 16, 2065-2085, https://doi.org/ 10.1175/JHM-D-14-0237.1.

Fu, G., S. P. Charles, and S. Kirshner, 2013: Daily rainfall projections from general circulation models with a downscaling nonhomogeneous hidden Markov model (NHMM) for southeastern Australia. Hydrol. Processes, 27, 3663-3673, https:// doi.org/10.1002/hyp.9483.

Gastineau, G., and C. Frankignoul, 2015: Influence of the North Atlantic SST variability on the atmospheric circulation during the twentieth century. J. Climate, 28, 1396-1416, https:// doi.org/10.1175/JCLI-D-14-00424.1.

Gill, A., 1980: Some simple solutions for heat-induced tropical circulation. Quart. J. Roy. Meteor. Soc., 106, 447-462, https:// doi.org/10.1002/qj.49710644905.

Gowda, P. H., J. Steiner, C. Olson, M. Boggess, T. Farrigan, and M. A. Grusak, 2018: Agriculture and rural communities. Impacts, Risks, and Adaptation in the United States: Fourth National Climate Assessment, Volume II. U.S. Global Change Research Program, https://doi.org/10.7930/NCA4.2018.CH10.

Groisman, P. Y., and D. R. Easterling, 1994: Variability and trends of total precipitation and snowfall over the United States and Canada. J. Climate, 7, 184-205, https://doi.org/10.1175/15200442(1994)007<0184:VATOTP>2.0.CO;2.

Hall, J. W., D. Grey, D. Garrick, F. Fung, C. Brown, S. J. Dadson, and C. W. Sadoff, 2014: Coping with the curse of freshwater variability. Science, 346, 429-430, https://doi.org/10.1126/science.1257890.

Hayhoe, K., and Coauthors, 2007: Past and future changes in climate and hydrological indicators in the US Northeast. Climate Dyn., 28, 381-407, https://doi.org/10.1007/s00382-006-0187-8.

Horel, J. D., 1981: A rotated principal component analysis of the interannual variability of the Northern Hemisphere $500 \mathrm{mb}$ height field. Mon. Wea. Rev., 109, 2080-2092, https://doi.org/ 10.1175/1520-0493(1981)109<2080:ARPCAO > 2.0.CO;2.

$\mathrm{Hu}, \mathrm{Z} . \mathrm{Z}$., and B. Huang, 2007: Physical processes associated with the tropical Atlantic SST gradient during the anomalous evolution in the southeastern ocean. J. Climate, 20, 3366-3378, https://doi.org/10.1175/JCLI4189.1.

Huang, B., and Coauthors, 2017: Extended reconstructed sea surface temperature, version 5 (ERSSTv5): Upgrades, validations, and intercomparisons. J. Climate, 30, 8179-8205, https://doi.org/ 10.1175/JCLI-D-16-0836.1.

Huang, H., J. M. Winter, and E. C. Osterberg, 2018: Mechanisms of abrupt extreme precipitation change over the northeastern United States. J. Geophys. Res. Atmos., 123, 7179-7192, https:// doi.org/10.1029/2017JD028136.

Huntington, T. G., and M. Billmire, 2014: Trends in precipitation, runoff, and evapotranspiration for rivers draining to the Gulf of Maine in the United States. J. Hydrometeor., 15, 726-743, https://doi.org/10.1175/JHM-D-13-018.1.

Kalnay, E., and Coauthors, 1996: The NCEP/NCAR 40-Year Reanalysis Project. Bull. Amer. Meteor. Soc., 77, 437-472, https:// doi.org/10.1175/1520-0477(1996)077<0437:TNYRP>2.0.CO;2.
Kao, H.-Y., and J.-Y. Yu, 2009: Contrasting eastern-Pacific and central-Pacific types of ENSO. J. Climate, 22, 615-632, https:// doi.org/10.1175/2008JCLI2309.1.

Kendall, M. G., 1955: Rank Correlation Methods. C. Griffin, 260 pp.

Kolb, T. E., C. J. Fettig, M. P. Ayres, B. J. Bentz, J. A. Hicke, R. Mathiasen, J. E. Stewart, and A. S. Weed, 2016: Observed and anticipated impacts of drought on forest insects and diseases in the United States. For. Ecol. Manage., 380, 321-334, https://doi.org/10.1016/j.foreco.2016.04.051.

Kunkel, K. E., D. R. Easterling, D. A. Kristovich, B. Gleason, L. Stoecker, and R. Smith, 2012: Meteorological causes of the secular variations in observed extreme precipitation events for the conterminous United States. J. Hydrometeor., 13, 1131-1141, https://doi.org/10.1175/JHM-D-11-0108.1.

, and Coauthors, 2013: Monitoring and understanding trends in extreme storms: State of knowledge. Bull. Amer. Meteor. Soc., 94, 499-514, https://doi.org/10.1175/BAMS-D-11-00262.1.

Kushnir, Y., R. Seager, M. Ting, N. Naik, and J. Nakamura, 2010: Mechanisms of tropical Atlantic SST influence on North American precipitation variability. J. Climate, 23, 5610-5628, https://doi.org/10.1175/2010JCLI3172.1.

Le, J., H. El-Askary, M. Allali, and D. C. Struppa, 2017: Application of recurrent neural networks for drought projections in California. Atmos. Res., 188, 100-106, https://doi.org/10.1016/ j.atmosres.2017.01.002.

Li, L., W. Li, and Y. Kushnir, 2012: Variation of the North Atlantic subtropical high western ridge and its implication to Southeastern US summer precipitation. Climate Dyn., 39, 1401-1412, https://doi.org/10.1007/s00382-011-1214-y.

Mann, H. B., 1945: Nonparametric tests against trend. Econometrica, 13, 245-259, https://doi.org/10.2307/1907187.

Marquardt Collow, A. B., M. G. Bosilovich, and R. D. Koster, 2016: Large-scale influences on summertime extreme precipitation in the northeastern United States. J. Hydrometeor., 17, 3045-3061, https://doi.org/10.1175/JHM-D-16-0091.1.

Marshall, J., and Coauthors, 2001: North Atlantic climate variability: phenomena, impacts and mechanisms. Int. J. Climatol., 21, 1863-1898, https://doi.org/10.1002/joc.693.

Melillo, J. M., T. C. Richmond, and G. W. Yohe, 2014: Climate change impacts in the United States: The Third National Climate Assessment. U.S. Global Change Research Program Rep., 841 pp., https://doi.org/10.7930/J0Z31WJ2.

Menne, M. J., I. Durre, R. S. Vose, B. E. Gleason, and T. G. Houston, 2012: An overview of the global historical climatology network-daily database. J. Atmos. Oceanic Technol., 29, 897-910, https://doi.org/10.1175/JTECH-D-11-00103.1.

Ning, L., E. E. Riddle, and R. S. Bradley, 2015: Projected changes in climate extremes over the northeastern United States. J. Climate, 28, 3289-3310, https://doi.org/10.1175/JCLI-D-14-00150.1.

Ossó, A., R. Sutton, L. Shaffrey, and B. Dong, 2018: Observational evidence of European summer weather patterns predictable from spring. Proc. Natl. Acad. Sci. USA, 115, 59-63, https:// doi.org/10.1073/pnas.1713146114.

Pederson, N., A. R. Bell, E. R. Cook, U. Lall, N. Devineni, R. Seager, K. Eggleston, and K. P. Vranes, 2013: Is an epic pluvial masking the water insecurity of the greater New York City region? J. Climate, 26, 1339-1354, https://doi.org/10.1175/JCLI-D-11-00723.1.

Peng, S., W. A. Robinson, and S. Li, 2002: North Atlantic SST forcing of the NAO and relationships with intrinsic hemispheric variability. Geophys. Res. Lett., 29, 1276, https:// doi.org/10.1029/2001GL014043.

Peterson, T.C., and Coauthors, 2013: Monitoring and understanding changes in heat waves, cold waves, floods, and droughts in 
the United States: State of knowledge. Bull. Amer. Meteor. Soc., 94, 821-834, https://doi.org/10.1175/BAMS-D-12-00066.1.

Rabiner, L. R., 1989: A tutorial on hidden Markov models and selected applications in speech recognition. Proc. IEEE, 77, 257-286, https://doi.org/10.1109/5.18626.

Robertson, A. W., S. Kirshner, and P. Smyth, 2004: Downscaling of daily rainfall occurrence over northeast Brazil using a hidden Markov model. J. Climate, 17, 4407-4424, https://doi.org/ 10.1175/JCLI-3216.1.

,,,--- S. P. Charles, and B. C. Bates, 2006: Subseasonalto-interdecadal variability of the Australian monsoon over North Queensland. Quart. J. Roy. Meteor. Soc., 132, 519-542, https://doi.org/10.1256/qj.05.75.

Ruprich-Robert, Y., R. Msadek, F. Castruccio, S. Yeager, T. Delworth, and G. Danabasoglu, 2017: Assessing the climate impacts of the observed Atlantic multidecadal variability using the GFDL CM2. 1 and NCAR CESM1 global coupled models. J. Climate, 30, 2785-2810, https://doi.org/10.1175/ JCLI-D-16-0127.1.

Schubert, S. D., and Coauthors, 2009: A U.S. CLIVAR project to assess and compare the responses of global climate models to drought-related SST forcing patterns: overview and results. J. Climate, 22, 5251-5272, https://doi.org/10.1175/2009JCLI3060.1.

_- and Coauthors, 2016: Global meteorological drought: A synthesis of current understanding with a focus on SST drivers of precipitation deficits. J. Climate, 29, 3989-4019, https:// doi.org/10.1175/JCLI-D-15-0452.1.

Seager, R., and M. Hoerling, 2014: Atmosphere and ocean origins of North American droughts. J. Climate, 27, 4581-4606, https://doi.org/10.1175/JCLI-D-13-00329.1.

— N N. Pederson, Y. Kushnir, J. Nakamura, and S. Jurburg, 2012: The 1960s drought and the subsequent shift to a wetter climate in the Catskill Mountains region of the New York city watershed. J. Climate, 25, 6721-6742, https://doi.org/10.1175/ JCLI-D-11-00518.1.

Steinman, B. A., M. E. Mann, and S. K. Miller, 2015: Atlantic and Pacific multidecadal oscillations and Northern Hemisphere temperatures. Science, 347, 988-991, https://doi.org/10.1126/ science. 1257856.

Steinschneider, S., and C. Brown, 2011: Influences of North Atlantic climate variability on low-flows in the Connecticut River Basin. J. Hydrol., 409, 212-224, https://doi.org/10.1016/ j.jhydrol.2011.08.038.

$\ldots$, and _ 2012a: Dynamic reservoir management with realoption risk hedging as a robust adaptation to nonstationary climate. Water Resour. Res., 48, W05524, https://doi.org/10.1029/ 2011WR011540.

_ and — 2012b: Forecast-informed low-flow frequency analysis in a Bayesian framework for the northeastern United States. Water Resour. Res., 48, W10545, https://doi.org/ 10.1029/2012WR011860.

Sutton, R.T., Hodson, D.L., 2005: Atlantic Ocean forcing of North American and European summer climate. Science, 309, 115-118, https://doi.org/10.1126/science.1109496.
Sweet, S. K., D. W. Wolfe, A. DeGaetano, and R. Benner, 2017: Anatomy of the 2016 drought in the Northeastern United States: Implications for agriculture and water resources in humid climates. Agric. For. Meteor., 247, 571-581, https://doi.org/ 10.1016/j.agrformet.2017.08.024.

Thyer, M., and G. Kuczera, 2000: Modeling long-term persistence in hydroclimatic time series using a hidden state Markov model. Water Resour. Res., 36, 3301-3310, https://doi.org/ 10.1029/2000WR900157.

Towey, K. L., J. F. Booth, A. Frei, and M. R. Sinclair, 2018: Track and circulation analysis of tropical and extratropical cyclones that cause strong precipitation and streamflow events in the New York City watershed. J. Hydrometeor., 19, 1027-1042, https://doi.org/10.1175/JHM-D-17-0199.1.

Trenberth, K. E., G. W. Branstator, D. Karoly, A. Kumar, N.-C. Lau, and C. Ropelewski, 1998: Progress during TOGA in understanding and modeling global teleconnections associated with tropical sea surface temperatures. J. Geophys. Res., 103, 14 291-14 324, https://doi.org/10.1029/97JC01444.

Visser, I., and M. Speekenbrink, 2010: depmixS4: An R package for hidden Markov models. J. Stat. Software, 36, 1-21, https:// doi.org/10.18637/jss.v036.i07.

Wang, C., S.-K. Lee, and D. B. Enfield, 2007: Impact of the Atlantic warm pool on the summer climate of the Western Hemisphere. J. Climate, 20, 5021-5040, https://doi.org/10.1175/JCLI4304.1.

,$- \ldots$, and -2008 : Atlantic warm pool acting as a link between Atlantic multidecadal oscillation and Atlantic tropical cyclone activity. Geochem. Geophys. Geosyst., 9, Q05V03, https://doi.org/10.1029/2007GC001809.

Wang, H., and S. Schubert, 2014: The precipitation response over the continental United States to cold tropical Pacific sea surface temperatures. J. Climate, 27, 5036-5055, https://doi.org/ 10.1175/JCLI-D-13-00453.1.

,$- \ldots$, M. Suarez, and R. Koster, 2010: The physical mechanisms by which the leading patterns of SST variability impact U.S. precipitation. J. Climate, 23, 1815-1836, https://doi.org/ 10.1175/2009JCLI3188.1.

Weaver, S. J., S. Schubert, and H. Wang, 2009: Warm season variations in the low-level circulation and precipitation over the central United States in observations, AMIP simulations, and idealized SST experiments. J. Climate, 22, 5401-5420, https:// doi.org/10.1175/2009JCLI2984.1.

Wilks, D. S., 2006: Statistical Methods in the Atmospheric Sciences. 2nd ed. International Geophysics Series, Vol. 100, Academic Press, 648 pp.

Wolfe, D. W., and Coauthors, 2018: Unique challenges and opportunities for northeastern US crop production in a changing climate. Climatic Change, 146, 231-245, https://doi.org/10.1007/ s10584-017-2109-7.

Wulff, C. O., R. J. Greatbatch, D. I. Domeisen, G. Gollan, and F. Hansen, 2017: Tropical forcing of the Summer East Atlantic pattern. Geophys. Res. Lett., 44, 11 166-11173, https://doi.org/ 10.1002/2017GL075493. 